\title{
The Neglected Role of Risk Mitigation Perception in the Risk Governance of Underground Technologies-The Example of Induced Seismicity
}

\author{
Lisa Haemmerli ${ }^{1} \cdot$ Michael Stauffacher $^{1}$
}

Accepted: 16 August 2020/Published online: 16 September 2020

(C) The Author(s) 2020

\begin{abstract}
Subsurface technologies, such as geothermal energy and carbon capture and storage, are options to help limit global warming. Subsurface technologies involve the risk of induced seismicity. The successful implementation of these technologies depends on the public perception of these risks. Risk governance frameworks propose assessing the level of public concern and designing adapted risk mitigation measures. We propose that concerns should not only be investigated with respect to the perceived risks but also with respect to the potential mitigation measures. We explore this by analyzing the perception of risk mitigation measures for different subsurface technologies. With an online survey $(N=808)$ in Switzerland we analyzed four technologies (in-between subject design) and four mitigation measures (within subject design). We found that risk mitigation measures are perceived differently, within and across technologies. Thus, public concerns about risk mitigation really matter. We suggest that future research should focus on how risk mitigation measures can be applied and communicated to realize the full potential of risk governance frameworks.
\end{abstract}

Keywords Carbon capture and storage - Enhanced geothermal systems · Induced seismicity · Risk mitigation perception $\cdot$ Shale gas $\cdot$ Switzerland

Lisa Haemmerli

lisa.haemmerli@hotmail.ch

1 D-USYS Transdisciplinarity Lab, Department of Environmental Systems Science (D-USYS), ETH Zurich (Swiss Federal Institute of Technology / Eidgenössische Technische Hochschule), 8092 Zurich, Switzerland

\section{Increasing Use of the Underground and Its Impact on Society}

The underground is increasingly important, as it provides resources and opportunities for disposal. For climate change mitigation, $\mathrm{CO}_{2}$ storage becomes more urgent, considering that nearly all scenarios rely on bioenergy with carbon capture and storage (BECCS) to achieve the $1.5^{\circ} \mathrm{C}$ target (van Vuuren et al. 2018). For the energy transition, geothermal energies can play an important role. With growing activities in the underground, several hazards, such as induced seismicity (IS) have been observed and raised concerns (Hirschberg et al. 2014; Grigoli et al. 2017). Induced seismicity is documented for carbon capture and storage (CCS), deep geothermal energy (DGE), and hydraulic fracturing for shale gas (SG), among others (Giardini 2009; Zoback and Gorelick 2012; Keranen et al. 2014; Zang et al. 2014). Induced seismicity can cause casualties (Grigoli et al. 2018), lead to increased media attention (Stauffacher et al. 2015), and evoke strong public reaction (Giardini 2009). Managing IS is one of the most relevant challenges in the underground, whenever stress or pore pressure is altered (Ellsworth 2013).

Tools for risk management are guidelines and frameworks to tackle IS. The most established framework has been developed by the U.S. Department of Energy for enhanced geothermal projects (Majer et al. 2012). It includes a stepwise instruction on how to deal with IS (Majer et al. 2012). Risk governance frameworks propose to integrate technical risk assessment with public concern assessments (IRGC 2012). Concern assessments can build on decades of studies on risk perception (Slovic 1987; Wilson et al. 2019). Trutnevyte and Wiemer (2017) proposed a screening tool to assess the level of concern related to IS before deciding on adapted risk mitigation measures. 
Risk mitigation measures should be considered, if impacts of seismicity appear greater than expected (Majer et al. 2012), or if social concern is high (Trutnevyte and Wiemer 2017).

While risk perception is considered essential in risk governance frameworks (Wachinger et al. 2013; Trutnevyte and Wiemer 2017), the perception of mitigation measures is not addressed. If public concerns matter, concerns should not only be investigated for risks but for proposed mitigation measures as well. It is possible, that mitigation measures are perceived differently and thus the concerns by the public are not fully addressed. We know of only one study that asked questions on risk mitigation perception for IS, focusing on gas production in the Netherlands (Perlaviciute et al. 2017). But the study did not discuss the implications of the results for risk governance. To our knowledge, the perception of risk mitigation measures for different technologies has not been studied. This is surprising, given that risk perception has been studied across technologies and countries in numerous studies.

This study analyzes how a sample of the Swiss public perceives various forms of risk mitigation that address the severity of the induced seismicity hazard at the source (traffic light system), exposure (relocation of the project to a remote area), vulnerability (structural retrofitting), and compensation (earthquake insurance). We examine risk mitigation perception for deep geothermal energy (DGE), hydraulic fracturing for shale gas (SG), carbon capture and storage (CCS), and $\mathrm{CO}_{2}$-plume geothermal (CPG). The technologies differ in their risk profiles, technological maturity, social discourse, and risk benefit perceptions (Dowd et al. 2011; Aposteanu et al. 2014; U.S. Department of Energy 2015; Thomas et al. 2017). Since CPG is still in the phase of basic technology research (Molnár et al. 2018; Wang et al. 2019), there was no public discourse yet; SG is widely used and discussed controversially (Williams et al. 2017); CCS and DGE are in between, with few installations worldwide and technological development ongoing (Reiner 2016). We conducted an online survey (808 respondents) in Switzerland, where these technologies have been discussed, are not fundamentally contested, and while they are known (with the exception of CPG), few fixed opinions have been developed.

\section{Methods}

We performed an online survey in Switzerland in July 2017. We analyzed the perception of four risk mitigation measures (within subject design). All four risk mitigation measures were presented to all respondents, but each respondent got only one subsurface technology (in-between subject design).

\subsection{Sample}

In total, 808 respondents from the German- and Frenchspeaking parts of Switzerland completed the survey, recruited through an online access panel. Because of unrealistic answers, we excluded one respondent from the analysis, leading to 807 respondents. We used a quota for gender, age, and the two language regions. Thus, gender and language ratio were balanced and representative for the Swiss population (Swiss Federal Statistical Office 2016). The age ranged from 18 to 85 years $(M=47.12$ years, $S D=15.00)$, which is slightly older than the average Swiss population ( $M=43.65$ years) (Swiss Federal Statistical Office 2016). Compared to the average Swiss population, the sample was better educated. A minority of 43 respondents $(5.3 \%)$ completed compulsory education (6 years of primary school and 3 years of secondary school, nine years in total), which was lower compared to the Swiss average of $12.6 \%$. The number of respondents who completed secondary education $(N=429,53.1 \%)$ was higher than the average in the Swiss population $(46.2 \%)$. Respondents who had completed the tertiary education level (41.6\%) were representative for the Swiss population average $(41.3 \%)$ (Swiss Federal Statistical Office 2017). An additional 284 respondents did not complete the full survey. The highest dropout rate was found for $\operatorname{CCS}(N=79)$, followed by CPG $(N=74)$, SG $(N=65)$, and DGE $(N=66)$.

\subsection{Procedure and Measurements}

We tested the perception of four underground technologies: deep geothermal energy (DGE), hydraulic fracturing for shale gas ( $\mathrm{SG}), \mathrm{CO}_{2}$-plume geothermal (CPG), and carbon capture and storage (CCS). The respondents were randomly assigned to one of the four underground technologies (between subject design). We tested the perception of the four risk mitigation measures by a within subject design.

The survey consisted of several parts. It first provided respondents with necessary information to reach an informed opinion. The information text included an illustration, adopted from Knoblauch et al. (2017) for DGE, SG, and CPG, and L'Orange Seigo et al. (2013) for CCS. The information texts were structured similarly as follows:

Deep Geothermal Energy Geothermal energy-also called underground heat-is energy stored in the subsurface. The amount of heat stored at the interior of the Earth is large. The deeper, the warmer it becomes. Temperature increases by $3{ }^{\circ} \mathrm{C}$ per $100 \mathrm{~m}$ on average from the Earth's surface. There are different technologies to use this energy. A distinction is made between deep geothermal energy and near-surface geothermal energy. Deep geothermal energy uses heat in up to $5 \mathrm{~km}$ depth for heating and in many cases 
for electricity generation. Water is pumped down, which is heated in the underground. With this technology, almost no greenhouse gases, such as carbon dioxide, are released.

Shale Gas Shale gas is a fuel stored below the Earth's surface. It is a fossil fuel and is mainly used for heating and electricity generation. When combusting shale gas, carbon dioxide (a greenhouse gas) is released. Shale gas is captured in small bubbles within rock formations. To produce shale gas, a borehole of up to $5 \mathrm{~km}$ depth has to be set up, followed by a horizontal bore, to crack the rock formations with high pressure and a mix of water, sand, and chemicals-this is called hydraulic fracturing. The difference between shale gas and conventional gas is the storage: conventional gas accumulates in reservoirs that can be tapped for production.

Carbon Capture and Storage Carbon dioxide $\left(\mathrm{CO}_{2}\right)$ is one of the most relevant greenhouse gases, which is mostly released into the atmosphere by the combustion of fossil fuels. The combustion of fossil fuels (oil, natural gas, and coal) generates large quantities of electricity and heat worldwide. With carbon capture and storage (CCS) a large part of these $\mathrm{CO}_{2}$ emissions are directly captured at the source of the power plants and stored in the underground. The captured $\mathrm{CO}_{2}$ is pumped through a borehole to a depth of at least 800 meters. For this purpose, the $\mathrm{CO}_{2}$ must be compressed so much that it is no longer gaseous. This ensures that carbon dioxide is not released into the atmosphere.

$\mathrm{CO}_{2}$-Plume Geothermal Geothermal energy-also called underground heat-is energy stored in the subsurface. The amount of heat stored at the interior of the Earth is large. The deeper, the warmer it becomes. Temperature increases by $3{ }^{\circ} \mathrm{C}$ per $100 \mathrm{~m}$ on average from the Earth's surface. There are different technologies to use this energy. A distinction is made between deep geothermal energy and near-surface geothermal energy. Deep geothermal energy uses heat in up to $5 \mathrm{~km}$ depth for heating and in many cases for electricity generation. Carbon dioxide $\left(\mathrm{CO}_{2}\right)$ is pumped down, which is heated in the underground. $\mathrm{CO}_{2}$ is one of the most relevant greenhouse gases. A part of this $\mathrm{CO}_{2}$, which is pumped into the depth, will be stored permanently in the underground. This ensures that carbon dioxide is not released into the atmosphere.

\subsubsection{Perception of the Technology}

Perception of the technology was assessed by means of a series of six evaluative semantic differential 7-point Likert scales (for example, "I think the technology is negative / positive, frightening / promising, retrograde / innovative, bad for the global environment / good for the global environment, bad for the local environment / good for the local environment, dangerous / safe" adapted from
Dütschke et al. (2016). Scores were calculated so that higher scores indicate a more favorable perception of the underground technology. We created an overall technology perception scale by calculating the mean values of the six categories. We classified scores below 3.5 as negative, between 3.5 and 4.5 as neutral, and scores above 4.5 as positive technology perception.

\subsubsection{Perception of Risk Mitigation Measures}

We measured the perception of four risk mitigation measures regarding induced seismicity (the measures used in the survey are described in the footnotes). Mitigation can be divided into direct and indirect measures. Direct measures aim to reduce seismicity. Examples are altering the injection rates, traffic light systems, structural retrofitting (Majer et al. 2012), changing the site location of the project, and relocation of the affected populations. Indirect measures focus on public/regulatory acceptance or operator liability and insurance, outreach, and benefit to the local community (Majer et al. 2012). The first mitigation measure "traffic light system" observes seismicity, and if a magnitude threshold is exceeded, operation will be adjusted to avoid greater damage (McGarr et al. 2015). "Structural retrofitting" 2 is more costly and not effective for non-structural damage (Bommer et al. 2015). "Changing the site location of the project" 3 to a remote location might impact the economic viability (Bommer et al. 2015). In the survey, we described relocation as changing the project site to a more remote area. "Insurance" ${ }^{4}$ is an indirect mitigation measure and compensates affected people financially.

We assessed the perception of mitigation measures on a 7-point Likert scale ( 1 = "I do not agree at all" to 7 = "I fully agree") using five categories in each case: "I think the measure traffic light system to reduce the risk of induced seismicity is necessary / effective / unnecessary [recoded so that highest agreement receives lowest value and vice

\footnotetext{
1 The traffic light system measure consists of real-time monitoring of earthquakes. The values for the colors of the traffic light system are predefined-Green: no earthquake registration or no earthquakes that give cause for serious concern, continuation of the drilling. Orange: indicates that the level of earthquake intensity is increasing towards an unacceptable level. The drilling procedure must be changed. Red: at this stage, the immediate suspension of the drilling is required.

2 The structural retrofitting measure intends to make buildings and infrastructure more earthquake-proof through structural provisions. In particular, the structures of buildings are reinforced.

3 The relocation measure intends to move the project to an area where fewer people live. This reduces the number of people that could be affected by an induced earthquake.

${ }^{4}$ The insurance against earthquake damage measure reduces the personal (financial) risk. In case of an earthquake, the cost of the damage caused will be refunded.
} 
versa] / I feel safe with the mitigation measure / I would approve the project with this measure." The categories "necessary" and "effective" were adapted from the study by Perlaviciute et al. (2017). We will refer to the categories as effectiveness, necessity, safety, and technology approval. The four measures traffic light system, structural retrofitting, earthquake insurance, and project relocation yielded an overall scale with excellent internal consistency (5 items, $\alpha=0.92$ ). Reliability tests for individual technologies and individual risk mitigation measures yielded very similar results (Table 1 ). We created an overall risk mitigation scale for each mitigation measure by calculating the mean values. Similarly, we calculated an overall perception scale across all four risk mitigation measures for each of the four categories effectiveness, necessity, safety, and technology approval.

\subsubsection{Preference of Risk Mitigation Measures}

We assessed the preference of risk mitigation measures by providing the opportunity to rank the four different risk mitigation measures according to the preferred order of importance. Weights are applied in reverse, so that a respondent's most preferred choice has the weight of 4 , and the least preferred choice (which was ranked in the last position) has a weight of 1 . We calculated the average ranking and examined the most preferred choice.

\subsubsection{Demographic Information}

The respondents indicated their age, gender, and level of education. The questionnaire included additional items that are not relevant to the present research.

\subsection{Statistical Analysis}

We used univariate analysis of variances (ANOVAs) to study the effects of the technologies on the respondents' perceptions of risk mitigation measures. Repeated measures ANOVAs were conducted to analyze the results across different risk mitigation measures (within subject design). If Levene's test of homogeneity of variances was significant for the dependent variables $(p<0.001)$ and the group sizes were unequal, we used Welch's F-test and Games-Howell as a post hoc test for statistical significance (Field 2013). Otherwise, we used Bonferroni post hoc testing.

\subsection{Experimental Check}

The four experimental conditions were balanced in terms of: language $\chi^{2}=0.85, p=0.84$ and gender $\chi^{2}=1.35$, $p=0.72$; whether respondents owned or rented a house or a flat $\chi^{2}=6.62, p=0.68$, and the size of the respondents' residences $F(3,803)=1.00, p=0.39$; and in terms of age $F(3,803)=0.98, p=0.40$ and education $F(3,803)=1.66$, $p=0.18$.

\section{Results}

The results are divided into three sections. First, the overall perception of the risk mitigation measures is analyzed. Subsequently, we present the perception of risk mitigation measures across technologies. Finally, we show the preference of risk mitigation measures across technology perception.

\subsection{Perception of Risk Mitigation Measures}

Respondents had to evaluate the effectiveness and the necessity of the risk mitigation measure, the subjective safety feeling, and if they would approve the technology project if such a measure was applied. The mean scores of these ratings for each mitigation measure are displayed in Table 2. The perception of effectiveness, necessity, safety, and technology approval differed significantly across the four mitigation measures (Fig. 1). The measures traffic light system and insurance are considered most needed, but relatively ineffective and less safe. Structural retrofitting and project relocation are perceived as less needed but more effective and safe.

With respect to effectiveness, safety, and technology approval, project relocation was perceived as the best and insurance the worst. Structural retrofitting was in-between, followed by traffic light system. Performing contrast analysis regarding safety revealed significant differences in all combinations. This is also true for effectiveness, except between the measures structural retrofitting $(M=4.48)$ and relocation $(M=4.63)$. Performing contrast analysis for the approval of the technology also revealed statistically significant differences between measures except for traffic light system $(M=3.64)$ and insurance $(M=3.56)$. However, with respect to necessity, traffic light system was perceived as the best, followed by insurance, structural retrofitting, and relocation. Performing contrast analysis only revealed statistically significant differences between relocation and all other measures.

To check which risk mitigation measure was preferred overall (see Fig. 1), we conducted repeated measures ANOVA. The results show that the perception significantly differed by the measure to mitigate the risk of induced seismicity, $F(2.83,2283.78)=14.55$. Post hoc tests using the Bonferroni correction revealed that the mitigation measure relocation $(M=4.49 \pm 0.048)$ was preferred over insurance $(M=4.20 \pm 0.050)$ and over the measure traffic 
Table 1 Cronbach's alpha by each technology

\begin{tabular}{|c|c|c|c|c|c|}
\hline & & DGE & SG & CPG & $\mathrm{CCS}$ \\
\hline Perception technology & Please indicate, what you spontaneously think of the technology. I find the technology... & 0.78 & 0.89 & 0.83 & 0.88 \\
\hline V1 & Negative-positive & & & & \\
\hline V2 & Bad-good for the global environment & & & & \\
\hline V3 & Innovative-retrogressive & & & & \\
\hline V4 & Encouraging-frightening & & & & \\
\hline V5 & Safe-risky & & & & \\
\hline V6 & Bad-good for the local environment & & & & \\
\hline Risk perception & I find the risk of induced earthquakes... & 0.82 & 0.75 & 0.82 & 0.80 \\
\hline V7 & Difficult to assess & & & & \\
\hline V8 & Considerable & & & & \\
\hline V9 & Too high & & & & \\
\hline V10 & Controllable & & & & \\
\hline Perception traffic light & I find the measure traffic light system to reduce the risk of induced earthquakes... & 0.86 & 0.84 & 0.86 & 0.85 \\
\hline V15 & Effective & & & & \\
\hline V16 & Needless* & & & & \\
\hline V17 & Necessary & & & & \\
\hline V18 & I would feel safer with this measure. & & & & \\
\hline V19 & I would approve the project with this measure. & & & & \\
\hline Perception retrofitting & I find the measure structural retrofitting to reduce the risk of induced earthquakes... & 0.86 & 0.79 & 0.83 & 0.86 \\
\hline V20 & Effective & & & & \\
\hline V21 & Needless* & & & & \\
\hline V22 & Necessary & & & & \\
\hline V23 & I would feel safer with this measure. & & & & \\
\hline V24 & I would approve the project with this measure. & & & & \\
\hline Perception insurance & I find the measure insurance to reduce the risk of induced earthquakes... & 0.84 & 0.81 & 0.87 & 0.86 \\
\hline V25 & Effective & & & & \\
\hline V26 & Needless* & & & & \\
\hline V27 & Necessary & & & & \\
\hline V28 & I would feel safer with this measure. & & & & \\
\hline V29 & I would approve the project with this measure. & & & & \\
\hline Perception relocation & I find the measure relocation to reduce the risk of induced earthquakes... & 0.87 & 0.82 & 0.88 & 0.85 \\
\hline V30 & Effective & & & & \\
\hline V31 & Needless* & & & & \\
\hline V32 & Necessary & & & & \\
\hline V33 & I would feel safer with this measure. & & & & \\
\hline V34 & I would approve the project with this measure. & & & & \\
\hline
\end{tabular}

$D G E$ deep geothermal energy, $S G$ hydraulic fracturing for shale gas, $C P G \mathrm{CO}_{2}$-plume geothermal, $C C S$ carbon capture and storage

*Recoded

light system $(M=4.32 \pm 0.047)$, which was statistically significant in both cases $(p<0.001$ and $p=0.003)$. Post hoc testing also revealed that the measure structural retrofitting $(M=4.41 \pm 0.045)$ was preferred over insurance $(M=4.20 \pm 0.050)$, which was also significant $(p<0.001)$. Therefore, we can conclude that the measures relocation and structural retrofitting are more desirable overall than the measures insurance and traffic light system.

A closer look at the evaluation of the mitigation measures showed that all four measures aggregated together are perceived as rather necessary $(M=4.90 \pm 0.041)$. But effectiveness $\quad(M=4.35 \pm 0.043), \quad$ safety $(M=3.95 \pm 0.050)$, and approval $(M=3.73 \pm 0.057)$ are seen as much more critical than necessity (Fig. 2). 
Table 2 Risk mitigation perception with four different criteria (within subject design, $N=807$ )

\begin{tabular}{llllll}
\hline & $\begin{array}{l}\text { Traffic light } \\
M(S D)\end{array}$ & $\begin{array}{l}\text { Retrofitting } \\
M(S D)\end{array}$ & $\begin{array}{l}\text { Insurance } \\
M(S D)\end{array}$ & $\begin{array}{l}\text { Relocation } \\
M(S D)\end{array}$ & $F(\mathrm{~d} 1, \mathrm{~d} 2)$ \\
\hline Effectiveness & $4.24(1.60)$ & $4.48(1.51)$ & $4.04(1.81)$ & $4.63(1.62)$ & $(2.93,2364.15) 34.40 * * *$ \\
Necessity & $5.00(1.59)$ & $4.89(1.51)$ & $4.98(1.70)$ & $4.73(1.68)$ & $(2.89,2327.39) 7.62 * * *$ \\
Safety & $3.85(1.74)$ & $4.12(1.70)$ & $3.58(1.87)$ & $4.24(1.71)$ & $(2.90,2336.40) 48.97 * * *$ \\
Technology approval & $3.64(1.79)$ & $3.77(1.81)$ & $3.56(1.88)$ & $3.95(1.84)$ & $(2.74,2207.13) 23.68 * * *$ \\
\hline
\end{tabular}

Values range from $1=$ low to $7=$ high

$* p<0.05$; ** $p<0.01 ; * * * p<0.001$

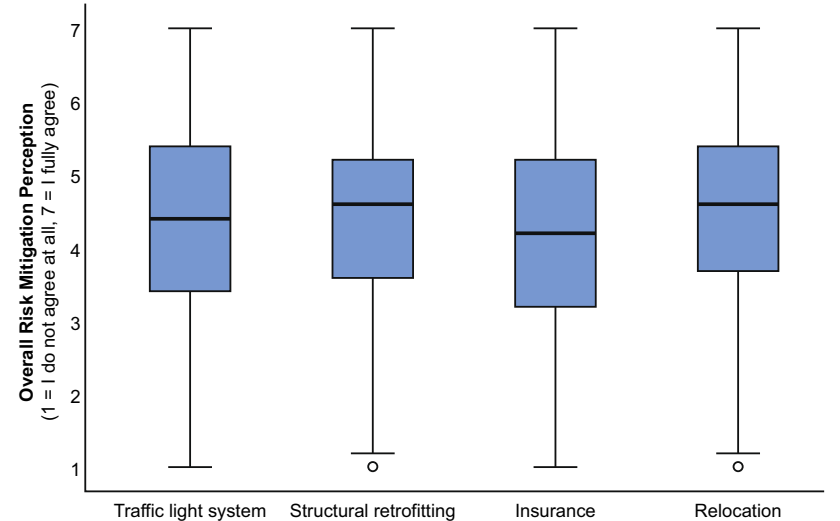

Fig. 1 Overall perception of risk mitigation measures (average of the four categories effectiveness, necessity, safety, and technology approval, $N=807$ )

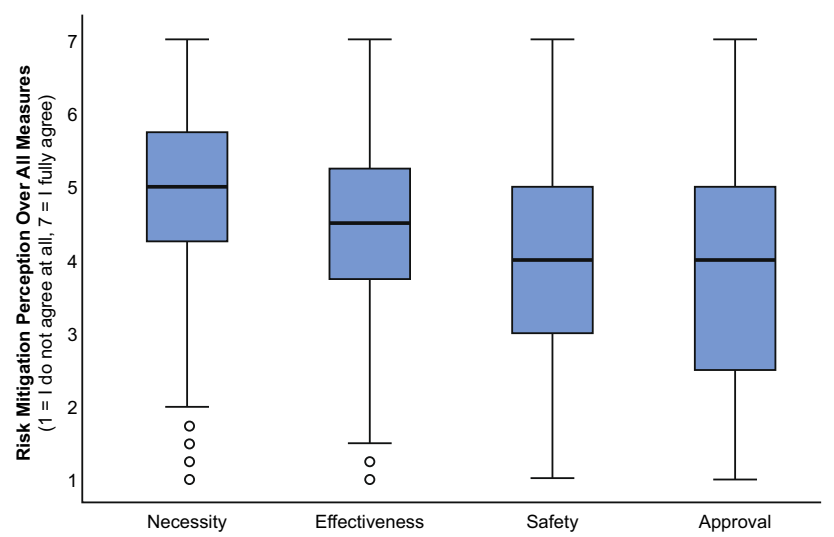

Fig. 2 Itemized perception of risk mitigation measures (average of the four mitigation measures traffic light, structural retrofitting, insurance, and relocation, $N=807$ )

\subsection{Perception of Risk Mitigation Measures across Technologies}

Univariate ANOVA revealed that the perception of the four mitigation measures differed significantly across technologies (Table 3). Bonferroni post hoc testing showed a significant difference between DGE $(M=4.56)$ and SG $(M=4.03)$ across all four measures $(p<0.001)$. Thus, respondents to DGE preferred all risk mitigation measures compared with the respondents to SG (Table 3). The perception of the risk mitigation measures traffic light system and structural retrofitting differed significantly between all technologies, except that there was no difference between DGE and CPG $(p=1)$ and between CCS and SG $(p=1)$, indicating that these measures were preferred by respondents to DGE and CPG over respondents to CCS and SG. The risk mitigation measure insurance was also perceived more positively by respondents to DGE and CPG, showing a significant difference between DGE and CCS $(p=0.002)$, DGE and SG, as well as SG and CPG $(p=0.009)$.

We conducted repeated measures ANOVA to check which measures were perceived differently across technologies. There was a significant (but small) interaction, $F(8.54,2285.54)=2.056, p=0.03$, indicating that the preference of the mitigation measures differed according to the technology. To break down this interaction, contrasts analysis was performed, comparing the perception of all risk mitigation measures across technologies. This revealed a significant interaction between the perception of the risk mitigation measures traffic light system and relocation across technologies, $F(3,803)=3.50, p=0.015$. This effect reflects that only respondents to CPG preferred the measure traffic light system over relocation. The other technologies preferred the measure relocation. For the rest, the preference ranking was the same (project relocation, structural retrofitting, traffic light system, earthquake insurance), but at different absolute levels (Table 3).

\subsection{Preference of Risk Mitigation Measures across Technology Perception}

We conducted a univariate ANOVA to examine the effect of the technology perception (negative, neutral, or positive) on risk mitigation measures preference. Levene's $\mathrm{F}$ test revealed that the homogeneity of variance assumption was 
Table 3 Risk mitigation perception (overall score across the four individual criteria necessity, effectiveness, safety, technology approval) by technology $(N=807)$-DGE; deep geothermal energy; SG: shale gas with hydraulic fracturing; $\mathrm{CPG} \mathrm{CO}_{2}$-plume geothermal; CCS: carbon capture and storage

\begin{tabular}{|c|c|c|c|c|c|}
\hline Risk mitigation perception & $\begin{array}{l}\mathrm{DGE} \\
N=209 \\
M(S D)\end{array}$ & $\begin{array}{l}\mathrm{SG} \\
N=200 \\
M(S D)\end{array}$ & $\begin{array}{l}\mathrm{CPG} \\
N=198 \\
M(S D)\end{array}$ & $\begin{array}{l}\mathrm{CCS} \\
N=200 \\
M(S D)\end{array}$ & $F(3,803)$ \\
\hline Traffic light system & $4.62(1.27)$ & $3.99(1.30)$ & $4.54(1.30)$ & $4.10(1.37)$ & $12.029 * * *$ \\
\hline Structural retrofitting & $4.63(1.24)$ & $4.08(1.23)$ & $4.63(1.19)$ & $4.28(1.34)$ & $9.690 * * *$ \\
\hline Earthquake insurance & $4.58(1.35)$ & $3.84(1.32)$ & $4.29(1.46)$ & $4.09(1.47)$ & $10.216^{* *}$ \\
\hline Relocation & $4.73(1.32)$ & $4.21(1.32)$ & $4.51(1.40)$ & $4.50(1.36)$ & $4.988 * *$ \\
\hline
\end{tabular}

Values range from $1=$ low to $7=$ high

$* p<0.05 ; * * p<0.01 ; * * * p<0.001$

Table 4 Preference of risk mitigation measures by technology perception $(N=807)$

\begin{tabular}{|c|c|c|c|c|}
\hline Measures & $\begin{array}{l}\text { Negative technology perception } \\
N=277 \\
M(S D)\end{array}$ & $\begin{array}{l}\text { Neutral technology perception } \\
N=218 \\
M(S D)\end{array}$ & $\begin{array}{l}\text { Positive technology perception } \\
N=312 \\
M(S D)\end{array}$ & $\begin{array}{l}\text { Welch's F } \\
F(2,506.92)\end{array}$ \\
\hline Traffic light system & $2.35(1.05)$ & $2.52(1.16)$ & $2.63(1.16)$ & $4.418^{*}$ \\
\hline Structural retrofitting & $2.64(0.95)$ & $2.61(1.00)$ & $2.75(0.97)$ & 2.748 \\
\hline Earthquake insurance & $1.92(1.00)$ & $2.20(1.02)$ & $2.21(1.03)$ & $7.181 * *$ \\
\hline Relocation & $3.08(1.14)$ & $2.67(1.23)$ & $2.41(1.23)$ & $23.733 * * *$ \\
\hline
\end{tabular}

Values range from $1=$ low preference to $4=$ high preference

$* p<0.05$; ** $p<0.01$; *** $p<0.001$

not met $(p<0.05)$ for some of the risk mitigation measures. As such, we used the Welch's F-test. The analysis showed that the effect of the technology perception on the preference of risk mitigation measures was significant for the measures traffic light system, insurance, and relocation (Table 4). A positive technology perception leads to a higher preference for the risk mitigation measures traffic light system and earthquake insurance. In the case of the measure relocation, a positive technology perception leads to a lower preference.

A closer look at the first choice of the risk mitigation measure revealed differences for the different technology perceptions. Respondents with a negative perception of the technology (regardless of the technology) preferred relocation, followed by structural retrofitting, traffic light system, and earthquake insurance. Respondents with a positive perception of the technology preferred different mitigation measures. They preferred the measure traffic light system, followed by relocation, structural retrofitting, and earthquake insurance (Fig. 3).

\section{Discussion}

Underground technologies pose the risk of induced seismicity. Risk governance proposes to integrate risk assessment and public concerns, resulting in recommendations

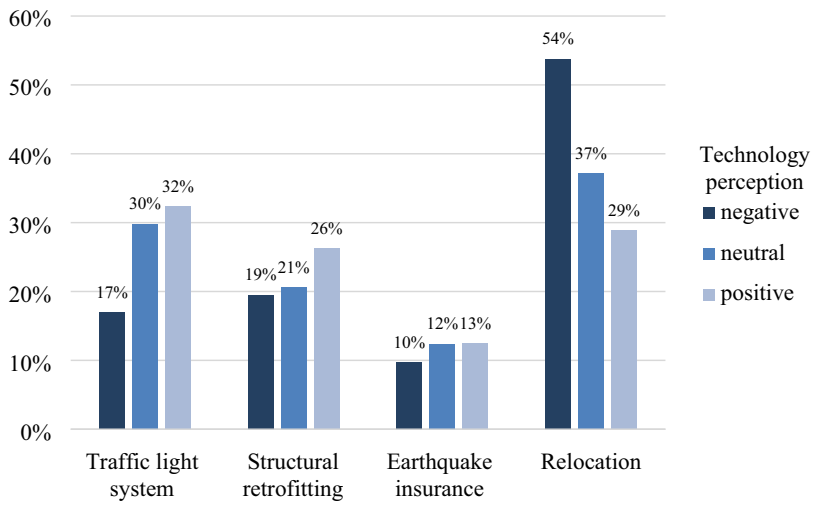

Fig. 3 Risk mitigation preference across technology perception $(N=807)$

for adapted risk mitigation measures. Yet, the perception of different risk mitigation measures is not addressed. We investigated the perception of four different measures across four underground technologies in Switzerland. Perceptions vary across measures and across technologies, showing that such concerns matter.

\subsection{Substantive Findings}

There are three substantive findings. First, mitigation measures are perceived differently. The mitigation 
measures project relocation and structural retrofitting are preferred over traffic light system and earthquake insurance. The least preferred mitigation measure, earthquake insurance, is also only reluctantly taken out for naturally occurring earthquakes (Heller et al. 2005; Brown 2013; Wachinger et al. 2013). Unlike most other mitigation measures, earthquake insurance needs action from the respondents themselves. As a result, insurance is probably less preferred. In general, direct mitigation measures, with the aim to reduce seismicity, are preferred over indirect measures. People prefer the hazard to be addressed directly and not for the potentially resulting consequences to be reduced.

Compensating the risk afterwards is viewed as less desirable than relocating the project and its potential hazards. The mitigation measure relocation is preferred over traffic light system and insurance. This could give us an indication that the public is especially sensitive with respect to their neighborhoods. This is in line with many studies around contested technology. With respect to CCS, for example, Krause et al. (2014) showed that $20 \%$ of the original proponents of a technology changed their minds after such a project was promoted in their neighborhood. Knoblauch and Trutnevyte (2018) also showed for deep geothermal energy that projects should be sited in remote areas, where the risk of induced seismicity is reduced, and the project is more accepted. The measure traffic light system is not perceived as particularly effective in comparison to the other mitigation measures. It might be that the public does not perceive this as a direct measure. In fact, real-time monitoring cannot always prevent seismic events, as there is a certain risk that some events occur even after the injection has stopped. Still, the traffic light system is considered to be best practice, especially for DGE (Kao et al. 2016). Thus, more dialogue with the public on the possibilities and challenges of traffic light systems would be reasonable. All risk mitigation measures are perceived more necessary than effective. This finding is in line with the longitudinal questionnaire study by Perlaviciute et al. (2017), which also found that most risk mitigation measures for earthquakes caused by gas production in the Netherlands were seen as more urgent than effective. The public wants mitigation measures, and finds them necessary, but people are not convinced that these measures will suffice. For risk governance, this means that polling risk mitigation perception is an essential input for choosing the appropriate set of mitigation measures and a respective risk governance scheme.

Second, mitigation measures are perceived differently across the four technologies. Our results show that all four mitigation measures are perceived more positively for a DGE project than for a SG project. The type of technology, and preexisting views and attitudes towards different technologies influence how the public perceives mitigation measures. This finding is comparable to the results of the study by Knoblauch et al. (2017) for risk communication with respect to induced seismicity. Attitude towards technology is a crucial factor in risk perception (Sjöberg 2000), and negative technology attitudes arguably lead to negative perceptions of risk mitigation measures as well. This can be supported with our results: DGE is perceived most positively, SG most negatively, similar to the risk mitigation perception. Still, the differences in risk mitigation perception are much smaller than for the technologies in general and not consistent across all four technologies. The differences are driven by other factors, arguably a combination of the differences in risk profiles, technological maturity, social discourse, and risk benefit perceptions (Dowd et al. 2011; Aposteanu et al. 2014; U.S. Department of Energy 2015; Knoblauch et al. 2017). Additional studies will be needed to better understand the variations in risk mitigation perception across technologies. For risk governance, this reaffirms the need to adapt measures according to the technology.

Third, we see that risk mitigation perception varies across and within different technologies. This has implications for risk governance, and concern assessment more specifically (IRGC 2012). We expect that the public will, dependent on the technology discussed, react differently to proposed risk mitigation measures. Thus, the public would conclude differently how well their concerns were taken into account and respond differently to the technology as well. This finding is comparable with a previous study, which analyzed three different hazards and showed that all hazard types required specific tailor-made mitigation approaches (de Vet et al. 2019). This is important for risk governance, as these frameworks generally assume that knowing about risk perception and designing risk mitigation measures accordingly (Trutnevyte and Wiemer 2017) would suffice. In fact, we can illustrate that neglecting such information will most probably lead to inadequate recommendations of risk mitigation measures within the scope of risk governance frameworks. Our study shows that we need to consider risk mitigation perception as well, as this can be important for the implementation of a technology.

\subsection{Limitations}

There is no Swiss history of fossil-based fuels, unlike in other countries such as Germany or the United States. Underground technologies are not very well known in the broad Swiss population. This is especially true for $\mathrm{CO}_{2}$ plume geothermal, which is still in the phase of basic technology research (Molnár et al. 2018; Wang et al. 2019). With respect to carbon capture and storage, there has not yet been a broad public discourse in Switzerland 
(unlike in other countries) and it is still unclear whether Switzerland is suitable for storing carbon dioxide. Thus, generalizations should be made with care and we strongly encourage researchers to replicate our study for other countries.

The sample in the study is slightly better educated and older than the Swiss population as a whole, comparable with other surveys (Mohorko et al. 2013). Also, a high dropout rate from the survey was recorded. But because the dropout rates were similarly high for the four technologies, the findings should not be biased when comparing between the technologies. However, it cannot be excluded, that this dropout rate had some impact on the findings.

\section{Conclusion}

Climate change mitigation and the energy transition both depend on technologies in the underground and this will become more important in the future. Yet, the respective technologies entail risks and will need carefully designed risk mitigation measures and respective dialogues with society. To date, these dialogues have been primarily based on the potential benefits of technologies and their risks, informed by risk perception and risk communication research. It is remarkable that research has not paid equal attention to risk mitigation. Our study is one of the first to study risk mitigation perception in detail and illustrates that risk mitigation perception varies across and within technologies, and matters for designing appropriate risk governance strategies.

In general, the perception of risk mitigation measures in our survey was less different than we expected given their very different nature. In our view, this shows that the public lacks experience in reflecting and discussing such measures for underground technologies. Society needs a new "literacy" for risk mitigation. This lack might also explain why preparedness in society for technological risk such as induced seismicity is far less developed than one would hope. Thus, it is not only a risk dialogue that is needed, but rather an integrated risk and risk mitigation dialogue as well. This is in line with the media study conducted by Stauffacher et al. (2015), who showed that media coverage is focused strongly on risks, but practically not at all on risk mitigation measures. However, we do not know enough about how various measures are perceived to inform such a dialogue.

Our explorative study showed that integrating social science research into the assessment and mitigation of risks of induced seismicity could contribute towards more comprehensive risk governance frameworks. Our study should be viewed as an invitation to other researchers to conduct similar and more detailed studies to explore the conditions and effects of risk mitigation perception. Future research should also focus on how risk mitigation measures can be applied and communicated, so that the potential of risk governance frameworks can be realized.

Acknowledgements The authors would like to thank Selma L'Orange Seigo, Olivier Ejderyan, Stefan Wiemer, and Michèle Marti for their valuable input. We would also like to express our gratitude to Theresa Arnold who provided insight and expertise that greatly assisted the research. This research was funded through the Swiss Competence Center for Energy Research-Supply of Electricity (SCCER-SoE); the Energy Turnaround National Research Program (NRP70) of the Swiss National Science Foundation; the European Union's ERA NET Cofund project ELEGANCY; and the Swiss Federal Office for Energy.

Open Access This article is licensed under a Creative Commons Attribution 4.0 International License, which permits use, sharing, adaptation, distribution and reproduction in any medium or format, as long as you give appropriate credit to the original author(s) and the source, provide a link to the Creative Commons licence, and indicate if changes were made. The images or other third party material in this article are included in the article's Creative Commons licence, unless indicated otherwise in a credit line to the material. If material is not included in the article's Creative Commons licence and your intended use is not permitted by statutory regulation or exceeds the permitted use, you will need to obtain permission directly from the copyright holder. To view a copy of this licence, visit http://creativecommons. org/licenses/by/4.0/.

\section{References}

Aposteanu, A., I. Berre, R. Bertani, C. Clauser, F. Jaudin, A. Kujbus, B. Sanner, and J. Urchueguia. 2014. Geothermal technology roadmap. Brussels, Belgium: European Technology Platform on Renewable Heating and Cooling.

Bommer, J.J., H. Crowley, and R. Pinho. 2015. A risk-mitigation approach to the management of induced seismicity. Journal of Seismology 19: 623-646.

Brown, A. 2013. Perception to action. Nature Climate Change 3: Article 98.

de Vet, E., C. Eriksen, K. Booth, and S. French. 2019. An unmitigated disaster: Shifting from response and recovery to mitigation for an insurable future. International Journal of Disaster Risk Science 10(2): 179-192.

Dowd, A.M., N. Boughen, P. Ashworth, and S. Carr-Cornish. 2011. Geothermal technology in Australia: Investigating social acceptance. Energy Policy 39(10): 6301-6307.

Dütschke, E., K. Wohlfarth, S. Höller, P. Viebahn, D. Schumann, and K. Pietzner. 2016. Differences in the public perception of CCS in Germany depending on $\mathrm{CO} 2$ source, transport option and storage location. International Journal of Greenhouse Gas Control 53: $149-159$.

Ellsworth, W.L. 2013. Injection-induced earthquakes. Science 341(6142): Article 1225942.

Field, A. 2013. Discovering statistics using IBM SPSS statistics. London: Sage Publications.

Giardini, D. 2009. Geothermal quake risks must be faced. Nature 462: 848-849.

Grigoli, F., S. Cesca, E. Priolo, A.P. Rinaldi, J.F. Clinton, T.A. Stabile, B. Dost, M.G. Fernandez, et al. 2017. Current challenges in monitoring, discrimination, and management of induced 
seismicity related to underground industrial activities: A European perspective. Reviews of Geophysics 55(2): 310-340.

Grigoli, F., S. Cesca, A.P. Rinaldi, A. Manconi, J.A. Lopez-Comino, J. Clinton, T. Dahm, R. Westaway, and S. Wiemer. 2018. The Mw 5.5 November 2017 South Korea Earthquake: An unusual event. Presented at the European Geosciences Union (EGU) General Assembly Conference 2018, 8-13 April 2018, Vienna, Austria.

Heller, K., D.B. Alexander, M. Gatz, B.G. Knight, and T. Rose. 2005. Social and personal factors as predictors of earthquake preparation: The role of support provision, network discussion, negative affect, age, and education. Journal of Applied Social Psychology 35(2): 399-422.

Hirschberg, S., S. Wiemer, and P. Burgherr. 2014. Energy from the Earth: Deep geothermal as a resource for the future? Zürich: vdf Hochschulverlag.

IRGC (International Risk Governance Council). 2012. An introduction to the IRGC Risk Governance Framework. Lausanne: International Risk Governance Council.

Kao, H., D.W.Eaton, G.M. Atkinson, S.C. Maxwell, and A.B. Mahani. 2016. Technical meeting on the traffic light protocols (TLP) for induced seismicity: Summary and recommendations. Open file no. 8075. Sidney, BC: Geological Survey of Canada.

Keranen, K.M., M. Weingarten, G.A. Abers, B.A. Bekins, and S. Ge. 2014. Sharp increase in central Oklahoma seismicity since 2008 induced by massive wastewater injection. Science 345(6195): 448-451.

Knoblauch, T.A.K., and E. Trutnevyte. 2018. Siting enhanced geothermal systems (EGS): Heat benefits versus induced seismicity risks from an investor and societal perspective. Energy 164(C): 1311-1325.

Knoblauch, T.A.K., M. Stauffacher, and E. Trutnevyte. 2017. Communicating low-probability high-consequence risk, uncertainty and expert confidence: Induced seismicity of deep geothermal energy and shale gas. Risk Analysis 38(4): 694-709.

Krause, R.M., S.R. Carley, D.C. Warren, J.A. Rupp, and J.D. Graham. 2014. "Not in (or under) my backyard": Geographic proximity and public acceptance of carbon capture and storage facilities. Risk Analysis 34(3): 529-540.

L'Orange Seigo, S., S. Dohle, L. Diamond, and M. Siegrist. 2013. The effect of figures in CCS communication. International Journal of Greenhouse Gas Control 16: 83-90.

Majer, E., J. Nelson, A. Robertson-Tait, J. Savy, and I. Wong. 2012. Protocol for addressing induced seismicity associated with enhanced geothermal systems. Washington, DC: Office of Energy Efficiency and Renewable Energy (EERE).

McGarr, A., B. Bekins, N. Burkardt, J. Dewey, P. Earle, W. Ellsworth, S. Ge, S. Hickman, et al. 2015. Coping with earthquakes induced by fluid injection. Science 347(6224): 830-831.

Mohorko, A., E. de Leeuw, and J. Hox. 2013. Internet coverage and coverage bias in Europe: Developments across countries and over time. Journal of Official Statistics 29(4): 609-622.

Molnár, L., M.O. Saar, and K.P. McDonnell. 2018. Feasibility study of $\mathrm{CO} 2$ plume geothermal system in Germany - Combining energy generation with carbon capture and storage. Biosystems and Food Engineering Research Review 23: 148-151.

Perlaviciute, G., L. Steg, E.J. Hoekstra, and L. Vrieling. 2017. Perceived risks, emotions, and policy preferences: A longitudinal survey among the local population on gas quakes in the Netherlands. Energy Research \& Social Science 29: 1-11.
Reiner, D.M. 2016. Learning through a portfolio of carbon capture and storage demonstration projects. Nature Energy 1: Article 15011.

Sjöberg, L. 2000. Factors in risk perception. Risk Analysis 20(1): $1-12$.

Slovic, P. 1987. Perception of risk. Science 236(4799): 280-285.

Stauffacher, M., N. Muggli, A. Scolobig, and C. Moser. 2015. Framing deep geothermal energy in mass media: The case of Switzerland. Technological Forecasting and Social Change 98: 60-70.

Swiss Federal Statistical Office. 2016. Permanent resident population by age, category of citizenship and sex (Altersmasszahlen der ständigen Wohnbevölkerung nach Staatsangehörigkeitskategorie und Geschlecht). https://www.bfs.admin.ch/bfs/de/home/statisti ken/bevoelkerung/stand-entwicklung/alter-zivilstand-staatsange hoerigkeit.assetdetail.80427.html. Accessed 21 Jul 2017 (in German).

Swiss Federal Statistical Office. 2017. Education level of the permanent resident population by age and sex (Bildungsstand der ständigen Wohnbevölkerung nach Alter und Geschlecht). https://www.bfs.admin.ch/bfs/de/home/statistiken/bildung-wis senschaft/bildungsindikatoren/themen/wirkung/bildungsstand. assetdetail.12527184.html. Accessed 21 Jul 2017 (in German).

Thomas, M., T. Partridge, B.H. Harthorn, and N. Pidgeon. 2017. Deliberating the perceived risks, benefits, and societal implications of shale gas and oil extraction by hydraulic fracturing in the US and UK. Nature Energy 2: Article 17054.

Trutnevyte, E., and S. Wiemer. 2017. Tailor-made risk governance for induced seismicity of geothermal energy projects: An application to Switzerland. Geothermics 65: 295-312.

U.S. Department of Energy. 2015. 2014 technology readiness assessment - A checkpoint along a challenging journey. Clean Coal Research Program. Washington, DC: U.S. Department of Energy

van Vuuren, D.P., E. Stehfest, D.E.H.J. Gernaat, M. van den Berg, D.L. Bijl, H.S. de Boer, V. Daioglou, J.C. Doelman, et al. 2018. Alternative pathways to the $1.5^{\circ} \mathrm{C}$ target reduce the need for negative emission technologies. Nature Climate Change 8: 391-397.

Wachinger, G., O. Renn, C. Begg, and C. Kuhlicke. 2013. The risk perception paradox - implications for governance and communication of natural hazards. Risk Analysis 33(6): 1049-1065.

Wang, Y., T. Li, Y. Chen, and G. Ma. 2019. Numerical analysis of heat mining and geological carbon sequestration in supercritical $\mathrm{CO}_{2}$ circulating enhanced geothermal systems inlayed with complex discrete fracture networks. Energy 173: 92-108.

Williams, L., P. Macnaghten, R. Davies, and S. Curtis. 2017. Framing 'fracking': Exploring public perceptions of hydraulic fracturing in the United Kingdom. Public Understanding of Science 26: 89-104.

Wilson, R.S., A. Zwickle, and H. Walpole. 2019. Developing a broadly applicable measure of risk perception. Risk Analysis 39(4): 777-791.

Zang, A., V. Oye, P. Jousset, N. Deichmann, R. Gritto, A. McGarr, E. Majer, and D. Bruhn. 2014. Analysis of induced seismicity in geothermal reservoirs-An overview. Geothermics 52: 6-21.

Zoback, M.D., and S.M. Gorelick. 2012. Earthquake triggering and large-scale geologic storage of carbon dioxide. Proceedings of the National Academy of Sciences 109(26): 10164-10168. 